Military Technical College

Kobry El-Kobba

Cairo, Egypt

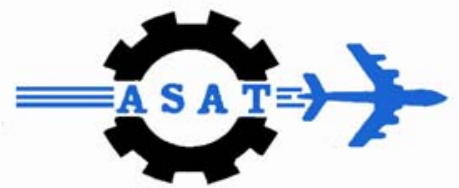

12-th International Conference

on

Aerospace Sciences \&

Aviation Technology

\title{
PRECIPITATE AGGLOMERATION MECHANISM
}

$\mathrm{BALIKCl}^{*} \mathrm{E}$.

\begin{abstract}
Superalloys are high tech materials used in aggressive atmospheres in aero-engines and land-base gas turbines. IN738LC is an important superalloy used in gas turbines. Main strengthening ingredient in this superalloy is the $\mathrm{Ni}_{3}(\mathrm{Al}, \mathrm{Ti}, \mathrm{Nb})$ type precipitate phase, which goes through size and morphological changes by the influence of temperature and time. Coarsening features of the precipitate phase in IN738LC are explored. Coarsening of precipitates is via agglomeration of nearby precipitates moving as a whole in the matrix. In contrast to conventionally accepted view of constant activation energy, experimental data in this study suggest varying activation energy which causes coalescence and relates to the precipitate size in the form of an increasing polynomial.
\end{abstract}

\section{KEY WORDS}

Superalloy, IN738LC, Precipitate coarsening, and Activation energy

\footnotetext{
* Assistant professor, Dpt. Of Mechanical Engineering, Bogazici University, Istanbul, Turkey.
} 


\section{INTRODUCTION}

Superalloys are high tech materials used in aggressive atmospheres in aero-engines and land-base gas turbines. Their prime candidacy for such applications is due to good corrosion resistance, optimal thermal properties, strength coupled with ductility, creep and fatigue resistance, and optimal impact/wear resistance. The unique set of properties required in these alloys is obtained by having an fcc Ni-base solid solution matrix which is hardened by solutes, carbides, and precipitates of $\mathrm{Ni}_{3}(\mathrm{Al}, \mathrm{Ti}, \mathrm{Nb})$ type intermetallic compounds.

IN738LC is an important superalloy used in gas turbines. Limited number of publications available on this superalloy indicates the importance of microstructure control affecting the physical and mechanical properties [1-7]. In this alloy, precipitates form in spherical shape which later coarsens to a cubical shape dictated by anisotropic elastic properties and surface energy. The unimodal cuboidal form is sustained up to about $700 \mathrm{~nm}$ size after which a bimodal precipitate distribution is observed [8-14].

A number of experimental and theoretical studies have been carried out to understand the coarsening features of the second phase precipitate particles [15-42]. Various investigators considered the coarsening behavior of positively or negatively misfitting precipitates in the matrix. Precipitate evolution progresses toward the minimization of the total free energy of the system, which has two contributingfactors: the interfacial surface energy and the elastic strain energy. Results have suggested that the elastic strain energy due to the elastic self-energy and the configurational energy of the particles could play an effective role during the coarsening of precipitates. At the early stages of coarsening, the interfacial energy dominates the morphological evolution, while after the precipitates reach a critical size; the elastic strain energy term takes over. Directional alignment of the coarsening precipitates along the elastically soft directions, <100 $>$ in the Ni alloy systems, has also been reported, and it has again been attributed to the tendency to minimize the free energy of the system.

In this work, coalescence of precipitates is investigated and a relationship between the activation energy and precipitate size is suggested.

\section{EXPERIMENTAL}

The material used in this study was the polycrystalline IN738LC superalloy provided by Howmet Corporation, Whitehall, Michigan, in the form of rods with $15 \mathrm{~mm}$ diameter and $110 \mathrm{~mm}$ length in HIPed (hot isostatic pressed) condition whose microstructure is shown in Fig. 1. Afterwards, various aging heat treatments were carried out under vacuum to observe precipitate microstructure evolution. Precipitate microstructure analysis started with conventional metallographic sample preparation then continued by SEM (Hitachi S-2460N) observations. The etchant used was the following: $33 \% \mathrm{HNO}_{3}+33 \%$ acetic acid $+33 \% \mathrm{H}_{2} \mathrm{O}+1 \% \mathrm{HF}$. Precipitate size and volume fraction in the various conditions were measured from the SEM micrographs 
in a McIntosh ${ }^{\circledR}$ computer using the Prism View Image Analysis \& Measurement program (ImageSet ${ }^{\mathrm{TM}}$ ), distributed by Dapple Systems, Inc., Sunnyvale, CA.

\section{RESULT AND DISCUSSIONS}

Precipitate microstructure evolution in the superalloy IN738LC has been extensively studied and reported by the author [8-13]. Only the relevant data will be presented here to explore the features of coarsening. Measured precipitate sizes given in Table 1 show coarsening with increased temperature.

Precipitates generally coarsen by picking up solute atoms from the matrix, driven by the atomic diffusion process. However, coarsening can also occur by precipitate agglomeration and this is found to be one of the modes for growth of precipitates in the duplex-size microstructure of the alloy IN738LC. The features shown in Fig. 2 are clearly indicative of the fact that the precipitate coarsening is not controlled by conventional atomic diffusion process, wherein the smaller precipitates dissolve into the matrix, the solute atoms diffuse toward the larger ones, and their absorption by the latter leads to the precipitate coarsening due to the familiar Gibbs-Thompson effect. This process, Ostwald ripening, has been studied widely [18-22]. Although this process may be occurring, the precipitate coarsening here is via the agglomeration (consolidation) of adjacent precipitates. This process can still be considered as activated by inter-diffusion of atoms at the interface leading to its migration in the direction of possible attractive force activating the migration of the precipitate as a whole in the matrix medium. The precipitate coalescence takes place at a nearly constant volume fraction in the superalloy IN738LC [8].

The first hypothesis (to the author's knowledge) on the precipitate movement in the matrix as a whole for agglomeration purposes was made by R. D. Doherty in 1982 [15]. Doherty indicated that the closely spaced precipitates could move toward each other and join by the removal of elastically strained matrix. Later, P. W. Voorhees and W. C. Johnson [16] did the first theoretical analysis (1988) of the particle migration in the matrix driven by the elastic stresses. They basically derived the formulae for growth rate and migration velocity of the mass center of precipitates, considering the elastic energies. Other authors also have considered the coalescence process by taking into account the lattice misfit, the applied stress, and the elastic properties of the constituent phases in the system [18,23-42]. General finding is that the sign of the misfit and the applied stress, the ratio of the elastic properties of the precipitate and the matrix phase, and the interfacial energy might significantly affect the precipitate evolution. Also, some of the results indicate an inverse coarsening [23-25], where smaller precipitates may grow at the expense of the larger ones due to the elastic interactions between the precipitates. This finding is just the opposite of the growth by Ostwald ripening.

The particle motion can be conceived to be due to the pull out of the face of the particles in the direction of attractive force acting between the merging precipitates and corresponding caving-in at the opposite tail end of the particle. The advancing front can be projected to be pulled-out by activating the diffusion of the solute atoms from the precipitates into the adjoining matrix planes at the interface. The matrix 
layers in contact with the interface are then projected to slowly convert to precipitate layers. Simultaneously, diffusion of the solvent atoms from the matrix layers into the precipitate layers at the interface occurring at the opposite tail end would convert the precipitate layers into the matrix. This mechanism could possibly be aided by the vacancy and/or dislocation concentration at the interface. Removal of the elastically strained matrix between the merging precipitates also positively contributes to the process.

In this study, to calculate the activation energy for the coalescence of the precipitates, slope of log (d) vs. $1 / T$ plot is employed, where $d$ is precipitate size and $\mathrm{T}$ is temperature. The ultimate aim is to better understand and define the nature of the activation energy required to coalesce the precipitates. The absence of any such study in the literature, to the author's knowledge, makes this analysis significant, although some attempts have been made earlier to formulate the force acting on or between the precipitates during directional alignment $[29,35,36]$.

Assuming linear variation of log (d) vs. 1/T in different temperature ranges, the activation energy for the $\gamma$ ' precipitate growth, $Q$, is calculated by segmenting the plot of $\log (\mathrm{d})$ vs. $1 / \mathrm{T}$, shown in Fig. 3 , into three parts $\left(850-950^{\circ} \mathrm{C}, 950-1050^{\circ} \mathrm{C}\right.$, and $1050-1120^{\circ} \mathrm{C}$ ), and three different activation energies are obtained from the slopes of these segments by utilizing

$$
d^{n}-d_{o}{ }^{n}=A t e^{-Q / R T}
$$

Here, $d_{0}$ is the initial precipitate size, $A$ is a pre-exponential constant, $t$ is aging time, and $R$ is the gas constant. An additional activation energy value for the growth of analogous coarse precipitates in the duplex-size precipitate microstructure was calculated for the aging treatment at $1140^{\circ} \mathrm{C}$. Plot of the four calculated activation energies mentioned above for precipitate growth vs. average temperature in the various temperature ranges is shown in Fig. 4. A best curve fit to the experimental data points for $Q$ varying with $T$ showed a polynomial form as follows:

$$
Q(T)=(2.3356 e-8) T^{4}-(9.313 e-5) T^{3}+(0.1382) T^{2}-(90.398) T+22175
$$

Traditionally, the activation energy, $Q$, which is the energy needed to initiate a process, is assumed to be constant for a temperature range as appears in the Arhenius equation. However, here an increasing polynomial dependency of $Q$ on $T$ is obtained. The continuously increasing activation energy for precipitate growth with increasing temperature is an interesting observation. Even higher activation energies have been reported for higher temperatures in the range 1150 to $1225^{\circ} \mathrm{C}$ [8-9], indicating sluggish growth at high temperatures and signaling the dissolution of precipitates.

The next attempt is to correlate the activation energy to the precipitate size and the inter-precipitate spacing. It is seen from the data in Table 1 that the size of the precipitates varies as a polynomial function of $\mathrm{T}$, given as follows:

$$
d_{c f}(T)=(3.30779 e-5) T^{3}-(0.116511) T^{2}+(137.333) T-54021.6
$$


Inter-precipitate spacing was measured and also calculated employing the sketch in Fig. 5 and Eq. 4 [43]:

$$
s=\left(\sqrt{1 / A_{f}}-1\right) d
$$

where $S$ is the spacing between adjacent particles and $A_{f}$ the area fraction. $A$ proportional dependence of $s$ with $d$ can be seen in Fig. 6, which indicates that the inter-particle spacing increases with increasing size of the precipitates. In the figure legends hereon, cf stands for curve fit, $\mathrm{c}$ for calculated, and $\mathrm{m}$ for measured. The analysis shows that both the size and spacing between the precipitates increase with an increase in temperature, since the growth takes place at a nearly constant volume fraction of the precipitates, as mentioned earlier. This means that the increased size of the precipitates as well as the increased spacing between the adjacent ones necessitate more energy to coalesce them for growth. The increasing activation energy with increasing precipitate size and inter-particle spacing is illustrated in Fig. 7. The $Q_{\mathrm{cf}}$ values are the activation energy values calculated using Eq. (2) at different temperatures, which yielded the corresponding precipitate size and interparticle spacing.

\section{The "Precipitate Agglomeration Model (PAM)"}

The requirement for more energy for the coalescence process could be better understood when a clear distinction between the processes for the growth is made; one via disintegration or dissolution followed by atomic diffusion and the other by coalescence (i.e., by the movement of particles as a whole). In the latter, since the whole particle needs to move, it could be deduced that larger the size and more the distance to be moved, the more energy it would require.

Based on the above presentation, a simple 'Precipitate Agglomeration Model (PAM)' is proposed. It is postulated that the consolidation of adjacent particles by particle motion is due to an attractive force $F_{A}$ exerted by the particles on one another. This attractive force is felt to be developed by the need to reduce the overall surface interfacial energy of the particles as well as the elastic strain energy of the matrix at the given temperature, which would be determined by the total surface area of the particle. The surface area of the particle is a function of the size ' $d$ ' of the particle and should be proportional to $d^{2}$. Hence, one can write:

$$
\mathrm{F}_{\mathrm{A}}=f\left(\mathrm{~d}^{2}\right) \text {, where ' } \mathrm{d} \text { ' is a function of temperature }
$$

Dragged by the attractive force $F_{A}$, the particles are drawn to each other and coalesce. Hence, the agglomeration energy can be postulated to be a function of the product of the attractive force and the inter-precipitate distance ' $s$ '. Since the interprecipitate spacing is linearly proportional to the precipitate size, as indicated in Eq. (8), the following can be suggested.

$$
\mathrm{Q}(\mathrm{d}) \propto\left(\mathrm{F}_{\mathrm{A}}\right) \cdot \mathrm{s} \propto f\left(\mathrm{~d}^{2}\right) \cdot f(\mathrm{~d}) \propto f\left(\mathrm{~d}^{3}\right)
$$


$Q_{c f}$ values obtained for the $d_{c f}$ values of Fig. 3, plotted in Fig. 7, are again replotted against $\mathrm{d}_{\mathrm{cf}}{ }^{3}$, which is shown in Fig. 8. The function governing the curve shown in this plot is determined to be a polynomial given below:

$$
Q=(4.96634 \mathrm{e}-23)\left(\mathrm{d}^{3}\right)^{3}-(2.57128 \mathrm{e}-14)\left(\mathrm{d}^{3}\right)^{2}+(5.11797 \mathrm{e}-6)\left(\mathrm{d}^{3}\right)+155
$$

This function represents an increasing dependency of $Q$ to $d^{3}$ (i.e., to volume and hence to mass of each particle) and represents the variation of $Q$ with the coarsening of the particles. Thus, it can be inferred that the agglomeration or consolidation energy is dependent on a function of the volume or the mass of the consolidating particles. Eq. (7) is a function coming out of the experimental data derived in this work. Further definition and refinement of the agglomeration energy is possible.

It is reported that coarsening slows down at high magnitude of the misfit, since the elastic strains are proportional to the square of the misfit [32]. This means that precipitates with larger sizes, having higher misfit and elastic strains, would not favor the growth, and more energy supply would be required to advance any further coarsening.

PAM proposes that the consolidation (activation) energy is also a function of $\mathrm{d}^{3}$. It may be possible in further attempts to define the attractive force $F_{A}$ in terms of interfacial surface energy and elastic property differences between the matrix phase and the precipitates and to devise a better system of equations based on the premises of precipitate agglomeration model proposed here in this article.

\section{CONLUSION}

Precipitate agglomeration is observed to be via merging of nearby precipitates as a whole in contrast to conventional Ostwald ripening. Analysis of experimentally determined precipitate size data shows that activation energy is proportional to the size and hence the mass of the precipitates and it increases with increased precipitate size and inter-precipitate spacing.

\section{REFERENCES}

[1] C. G. Bieber, Suffern, and J. J. Galka: United States Patent Office, No: 3459545, August 1969.

[2] Mukherji, D., Jiao, F., Chen, W., and Wahi, R.P., "Stacking-fault Formation in Gamma' Phase During Monotonic Deformation of IN738LC at Elevatedtemperatures", Acta Metall. Mater., vol. 39(7), pp. 1515-1524, (1991).

[3] Li, J., Wahi, R.P., Chen, H., Chen, W., and Wever, H., "Deformation Substructure in the Nickel-base Alloy-IN738LC Under Superimposed CreepFatigue Loading", Z. Metallkunde, vol. 84(4), pp. 268-272, (1993).

[4] Li, J. and Wahi R.P., "Investigation of Gamma/Gamma' Lattice Mismatch in the Polycrystalline Nickel-base Superalloy IN738LC - Influence of Heat-Treatment and Creep Deformation", Acta Metall. Mater., vol. 43(2), pp. 507-517, (1995). 
[5] Wang, Y., Mukherji, D., Chen, W., Kutter, T., Wahi, R.P. and Wever, H., "The Cyclic Creep-Behavior of Nickel-Base Superalloy IN738LC", Z. Metallkunde, vol. 86(5), pp. 365-370, (1995).

[6] Bettge, D., Osterle, W. and Ziebs, J., "Temperature-Dependence of Yield Strength and Elongation of the Nickel-Base Superalloy IN738LC and the Corresponding Microstructural Evolution", Z. Metallkunde, vol. 86(3), pp. 190197, (1995).

[7] Jiao, F., Zhu, J., Wahi, R. P., Chen, H., Chen, W., and Wever, H., Proc. Conf. "LCF and Elasto-Plastic Behavior of Materials", Ed. by K. T. Rie, Elsevier Applied Science, London, pp. 298-303, (1992).

[8] Balikci, E., Raman, A. and Mirshams, R.A., "Influence of Various Heat Treatments on the Microstructure of Polycrystalline IN738LC", Metallurgical and Materials Transactions A, volume 28A, pp. 1993-2003, (1997).

[9] Balikci, E., Mirshams, R.A. and Raman, A., "Microstructure Evolution in Polycrystalline IN738LC in the Range 1120 to $1250^{\circ} \mathrm{C}$ ", Z, Metallkunde, vol. 90, pp. 132-140, (1999).

[10] Balikci, E., Ferrell, Jr., R.E. and Raman, A., "Preferred Orientations in the Superalloy IN738LC After Different Aging Heat Treatments", Z. Metallkunde, vol. 90, pp. 141-146, (1999).

[11] Balikci, E., Raman, A. and Mirshams, R.A., "Microstructure and Texture Effect on the Thermal Expansion of a Variously Aged Polycrystalline Superalloy IN738LC", Metallurgical and Materials Transactions A, volume 30A, pp. 28032808, (1999).

[12] Balikci, E., Mirshams, R.A. and Raman, A., "Fracture Behavior of the Superalloy IN738LC with Various Precipitate Microstructures", Materials Science and Engineering A, vol. 265A, pp. 50-62, (1999).

[13] Balikci, E., Mirshams, R.A. and Raman, A., "Tensile Strengthening in NickelBase Superalloy IN738LC", Journal of Materials Engineering and Performance, volume 9(3), pp. 324-329, (2000).

[14] Roy, I., Balikci, E., Ibekwe, S., Raman, A., "Precipitate Growth Activation Energy Requirements in the Duplex Size $V^{\prime}$ Distribution in the Superalloy IN738LC", Journal of Materials Science, volume 40, pp. 6207-6215, (2005).

[15] Doherty, R.D., "Role of Interfaces in Kinetics of Internal Shape Changes", Metal Science, vol. 16, pp 1-13, (1982).

[16] Voorhees, P.W. and Johnson, W.C., "Development of Spatial Correlations During Diffusional Late-Stage Phase-Transformations in Stressed Solids", Phys. Rev. Let., vol. 61(19), pp. 2225-2228, (1988).

[17] Davies, C.K.L., Nash, P. and Stevens, R.N., "Effect of Volume Fraction of Precipitate on Ostwald Ripening", Acta Metall., vol. 28, pp. 179-189, (1980).

[18] Tsumuraya, K. and Miyata, Y., "Coarsening Models Incorporating Both Diffusion Geometry and Volume Fraction of Particles", Acta Metall., vol. 31(3), pp. 437-452, (1983).

[19] Johnson, W.C., Voorhees, P.W. and Zupon, D.E., "The Effects of Elastic Stress on the Kinetics of Ostwald Ripening - The 2-Particle Problem", Metal. Trans., vol. 20A, pp. 1175-1189, (1989).

[20] Calderon, H.A., Voorhees, P.W., Murray, J.L. and Kostorz, G., "Ostwald Ripening in Concentrated Alloys", Acta Metall. Mater., vol. 42(3), pp. 991-1000, (1994). 
[21] Wolfsdorf, T.L, Bender, W.H. and Voorhees, P.W., "The Morphology of High Volume Fraction Solid-Liquid Mixtures: An Application of Microstructural Tomography", Acta Mater., vol. 45(6), pp. 2279-2295, (1997).

[22] Ricks, R.A., Porter, A.J. and Ecob R.C., "The Growth of Gamma'-Precipitates in Nickel-Base Super-Alloys", Acta Metall., vol. 31, pp. 43-53, (1983).

[23] Su, C.H. and Voorhees, P.W., "The Dynamics of Precipitate Evolution in Elastically Stressed Solids. 1. Inverse Coarsening”, Acta Mater., vol. 44(5), pp. 1987-1999, (1996).

[24] Johnson, W.C. and Voorhees, P.W., "Elastic Interaction and Stability of Misfitting Cuboidal Inhomogeneities", J. Appl. Phys., vol. 61(4), pp. 1610-1619, (1987).

[25] Johnson, W.C., Abinandanan, T.A., Voorhees, P.W., "The Coarsening Kinetics of 2 Misfitting Particles in an Anisotropic Crystal", Acta Metall. Mater., vol. 38(7), pp. 1349-1367, (1990).

[26] McCormack, M., Khachaturyan, A.G. and Morris, J.W., "A 2-Dimensional Analysis of the Evolution of Coherent Precipitates in Elastic Media", Acta Metall. Mater., vol. 40(2), pp. 325-336, (1992).

[27] Abinandanan, T.A. and Johnson, W.C., "Coarsening of Elastically Interacting Coherent Particles. 1. Theoretical Formulation”, Acta Metall. Mater., vol. 41(1), pp. 17-25, (1993).

[28] Wang, Y., Chen, L.Q. and Khachaturyan, A.G., "Kinetics of Strain-Induced Morphological Transformation in Cubic Alloys With a Miscibility Gap", Acta Metall. Mater., vol. 41(1), pp. 279-296, (1993).

[29] Socrate, S. and Parks, D.M., "Numerical Determination of the Elastic Driving Force for Directional Coarsening in Ni-Superalloys", Acta Metall. Mater., vol. 41(7), pp. 2185-2209, (1993).

[30] Abinandanan, T.A. and Johnson, W.C., "Coarsening of Elastically Interacting Coherent Particles. 2. Simulations of Preferential Coarsening and Particle Migrations", Acta, Metall. Mater., vol. 41(1), pp. 27-39, (1993).

[31] Hort, W. and Johnson, W.C., "Diffusional Boundary-Conditions During Coarsening of Elastically Interacting Precipitates", Metall. and Mater. Trans., vol. 25A, pp. 2695-2703, (1994).

[32] Fahrmann, M., Fratzl, P., Paris, O., Fahrmann, E. and Johnson, W.C., "Influence of Coherency Stress on Microstructural Evolution in Model Ni-Al-Mo Alloys", Acta Metall. Mater., vol. 43(3), pp. 1007-1022, (1995).

[33] Wang, Y. and Khachaturyan, A.G., "Shape Instability During Precipitate Growth in Coherent Solids", Acta Metall. Mater., vol. 43(5), pp. 1837-1857, (1995).

[34] Huh, J.Y. and Johnson, W.C., "Intrinsic Thermodynamic Stability of Stressed Coherent Systems", Acta Metall. Mater., vol. 43(4), pp. 1631-1642, (1995).

[35] Su, C.H. and Voorhees, P.W., "The Dynamics of Precipitate Evolution in Elastically Stressed Solids. 2. Particle Alignment", Acta Mater., vol. 44(5), pp. 2001-2016, (1996).

[36] Nabarro, F.R.N., Cress, C.M. and Kotschy, P., "Thermodynamic Driving Force for Rafting in Superalloys", Acta Mater., vol. 44(8), pp. 3189-3198, (1996).

[37] Gurtin, M.E. and Voorhees, P.W., "The Thermodynamics of Evolving Interfaces Far from Equilibrium", Acta Mater., vol. 44(1), pp. 235-247, (1996).

[38] Svoboda, J. and Lukas, P., "Modelling of Kinetics of Directional Coarsening in Ni-Superalloys", Acta Mater., vol. 44(6), pp. 2557-2565, (1996). 
[39] Johnson, W.C., "Effect of Elastic Stress on Two-Phase Binary Diffusion Couples", Metall. and Mater. Trans., vol. 28A, pp. 27-38, (1997).

[40] Mou, Y. and Howe, J.M., "Diffusion Fields Associated with Sizeland Shape Coarsening of Oblate Spheroids", Metall. and Mater. Trans., vol. 28A, pp. 3950, (1997).

[41] Mou, Y. and Howe, J.M., "Diffusion Fields Associated with Prolate Spheroids in Size and Shape Coarsening", Acta Mater., vol. 45(2), pp. 823-835, (1997).

[42] Li, D.Y. and Chen, L.Q., "Shape of a Rhombohedral Coherent Ti11Ni14 Precipitate in a Cubic Matrix and Its Growth and Dissolution During Constrained Aging", Acta Mater., vol. 45(6), pp. 2435-2442, (1997).

[43] Agarwal, B.D. and Broutman, L.J., Analysis and Performance of Fiber Composites, $2^{\text {nd }}$ ed., John Wiley \& Sons, Inc., New York, NY, p. 141, (1990). 


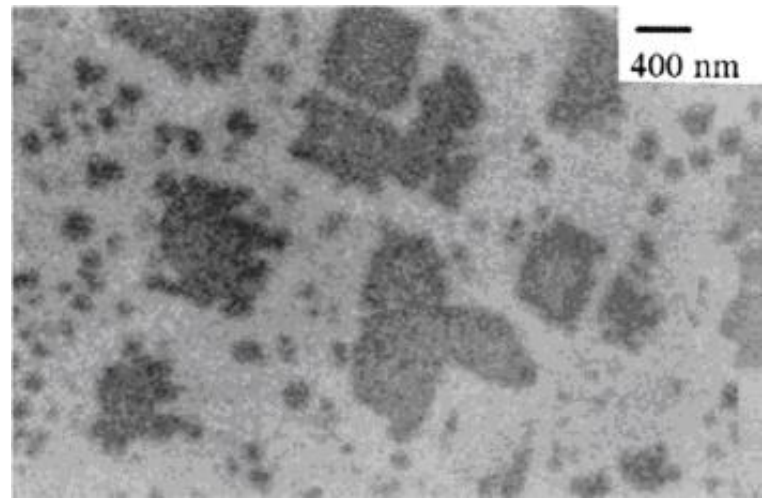

Figure 1. Precipitate microstructure of as received IN738LC. Small and large dark features are precipitates
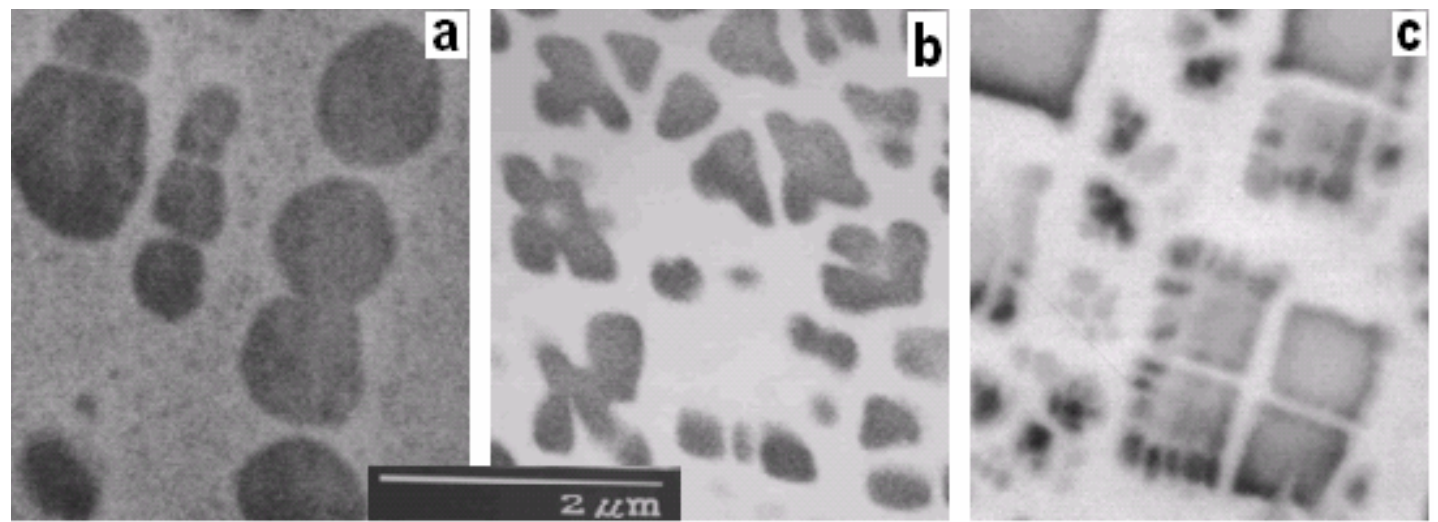

Figure 2. SEM micrographs showing coalescence of precipitates

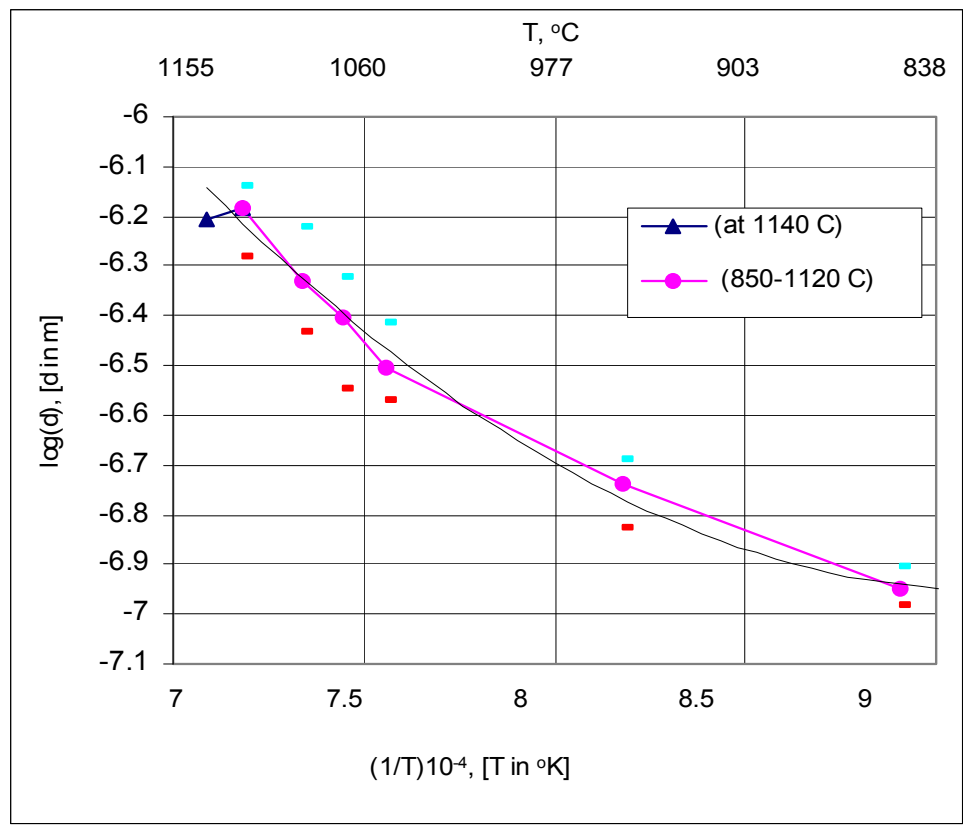

Figure 3. Plot of log(d) vs. 1/T of $\gamma^{\prime}$ size. Black continues curve is best fit to the experimental size data 


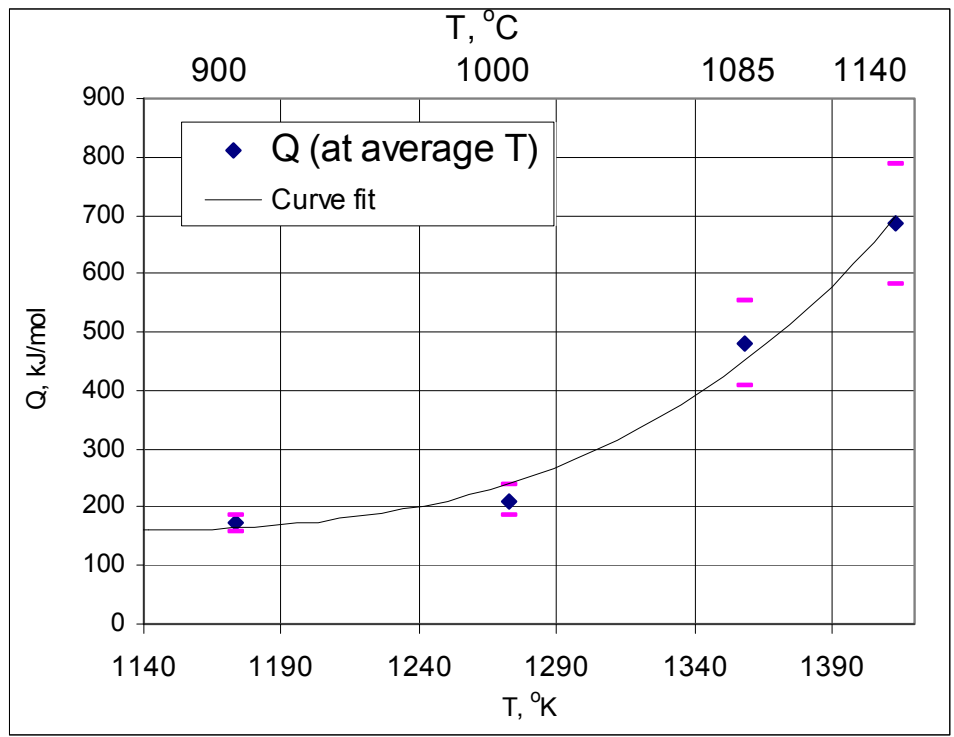

Figure 4. Plot of $Q$ vs. T

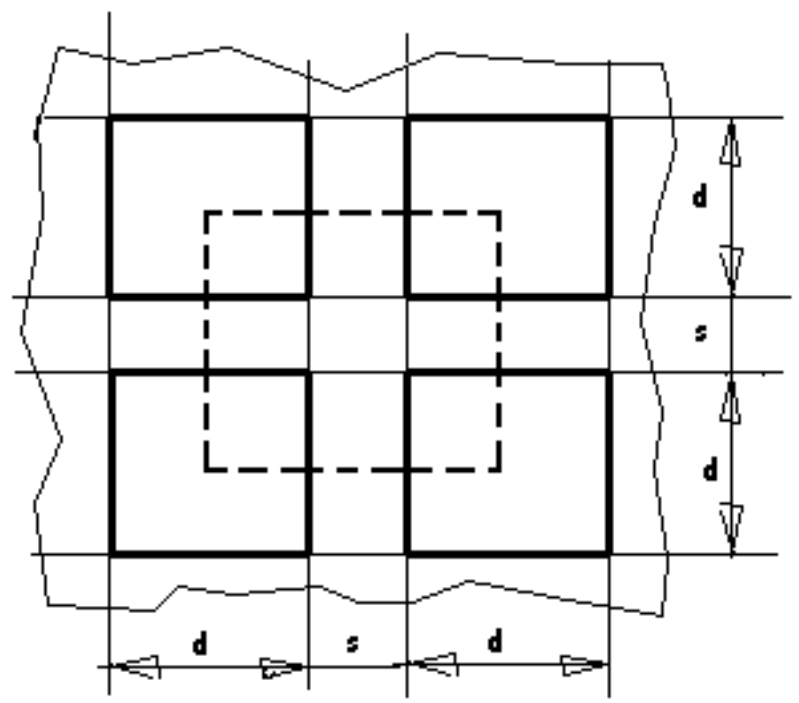

Figure 5. Evenly distributed cuboidal precipitates in the matrix. The dashed line shows the unit cell used to calculate the spacing (s) between the precipitates 


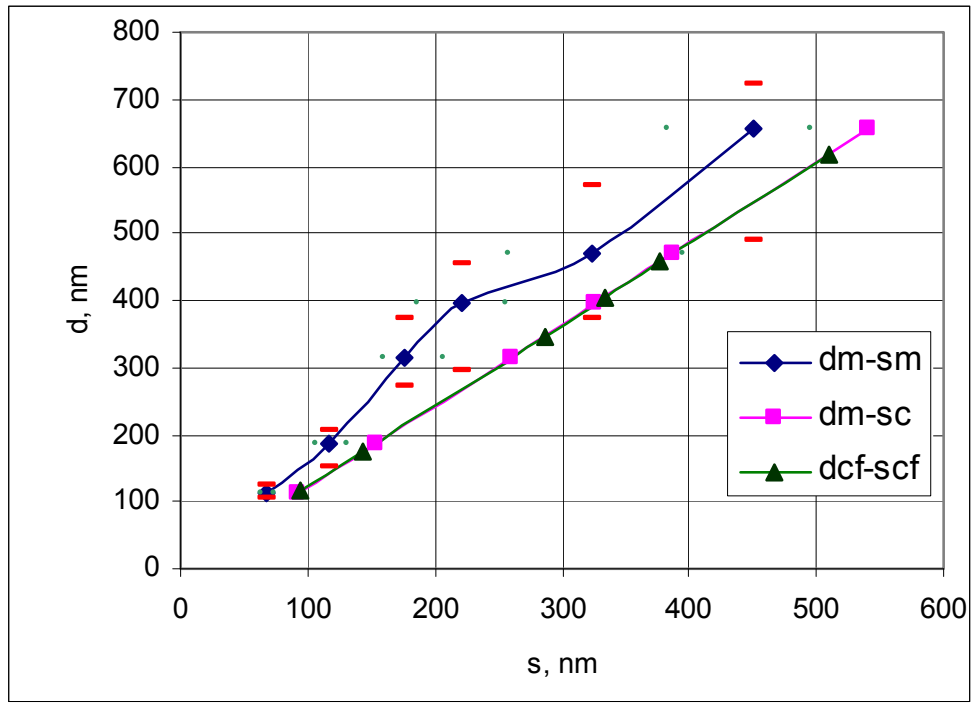

Figure 6. Plot of $d$ vs. s

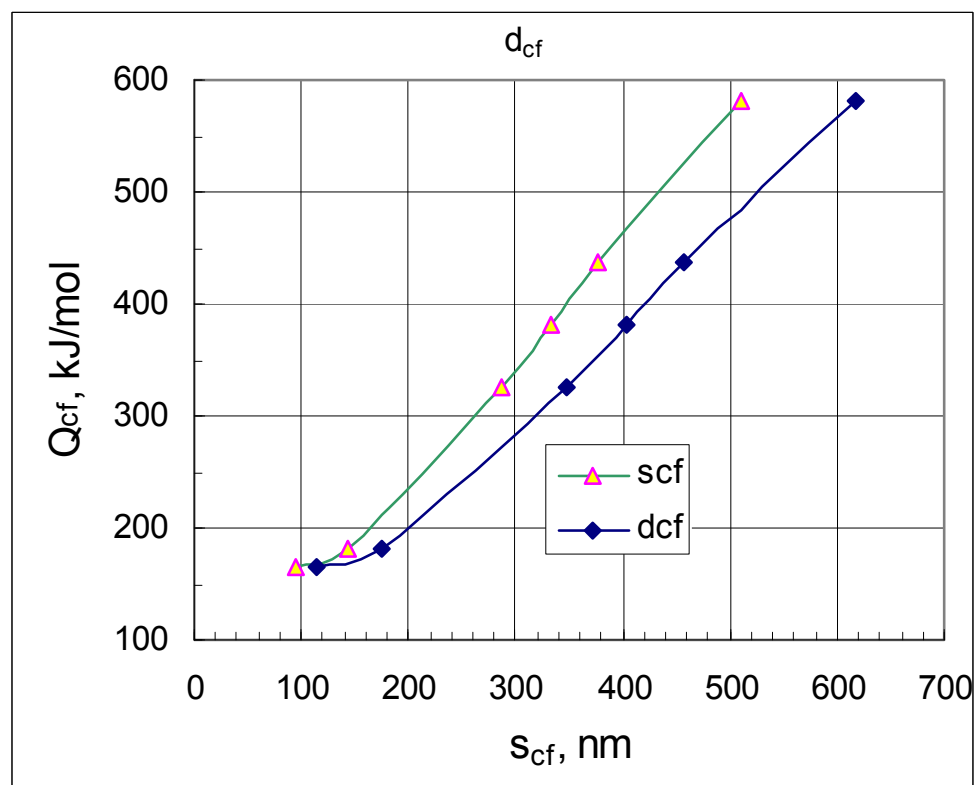

Figure 7. Plot of $Q_{c f}$ vs. $d_{c f}$ and $s_{c f}$ 


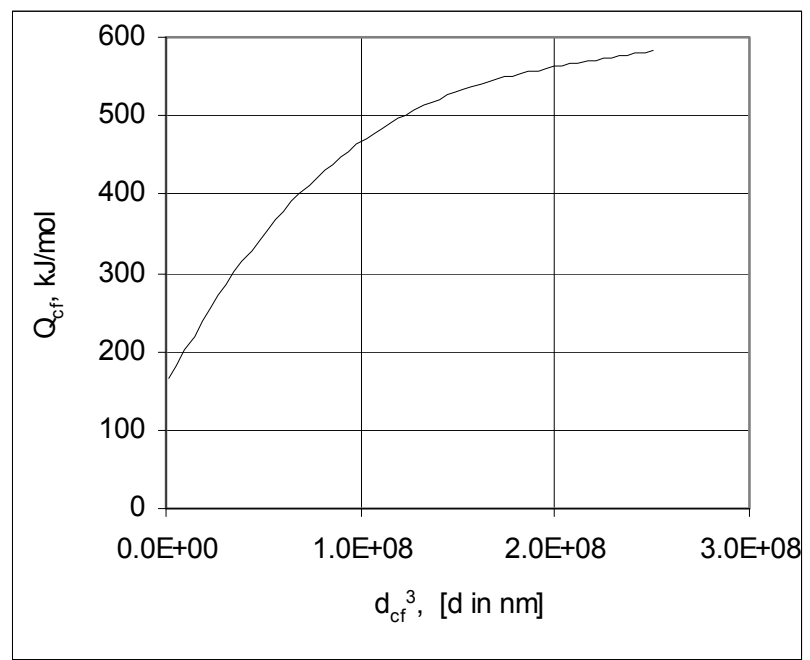

Figure 8. Plot of $Q_{\mathrm{cf}}$ vs $\mathrm{d}_{\mathrm{cf}}^{3}$

Table 1. Size of the $\gamma^{\prime}$ precipitates in water quenched conditions after aging for $24 \mathrm{~h}$ subsequent to solutionizing at $1200^{\circ} \mathrm{C}$ which yields a unimodal size of $\sim 70 \mathrm{~nm}$ precipitates

\begin{tabular}{|l|c|c|c|c|c|c|c|c|}
\hline $\begin{array}{l}\text { Aging temperature, } \\
{ }^{\mathbf{0}} \mathbf{C}\end{array}$ & $\mathbf{8 5 0}$ & $\mathbf{9 5 0}$ & $\mathbf{1 0 5 0}$ & $\mathbf{1 0 7 0}$ & $\mathbf{1 0 9 0}$ & $\mathbf{1 1 2 0}$ & $\mathbf{1 1 4 0}$ & $\mathbf{1 2 0 0}$ \\
\hline Precipitate Size, $\mathbf{n m}$ & $\begin{array}{c}112 \\
(1080) \\
{[-6 /+10]}\end{array}$ & $\begin{array}{c}187 \\
(430) \\
{[-19 /+10]}\end{array}$ & $\begin{array}{c}315 \\
(135) \\
{[-14 /+18]}\end{array}$ & $\begin{array}{c}395 \\
(72) \\
{[-25 /+15]}\end{array}$ & $\begin{array}{c}468 \\
(58) \\
{[-20 /+22]}\end{array}$ & $\begin{array}{c}655 \\
(32) \\
{[-25 /+10]}\end{array}$ & $\begin{array}{c}622 \\
(28) \\
{[-22 /+25]}\end{array}$ & $\begin{array}{c}70 \\
(1800) \\
{[ \pm 3]}\end{array}$ \\
\hline
\end{tabular}

First line in each data cell gives the average precipitate size, second line number of precipitate particles averaged, and third line \% deviation in size of the precipitates. Number of precipitates is given in a $4 \times 5$ in. ${ }^{2}$ area. 